\title{
Lipoxin $\mathrm{B}_{4}$ promotes the resolution of allergic inflammation in the upper and lower airways of mice
}

\author{
L Karra ${ }^{1}, \mathrm{O}$ Haworth $^{2}$, R Priluck ${ }^{2}$, BD Levy ${ }^{2,3}$ and F Levi-Schaffer ${ }^{1,3}$
}

Chronic mucosal inflammation is the hallmark of important and common airway diseases, such as allergic rhinitis (AR) and asthma. Lipoxin $\mathrm{A}_{4}\left(\mathrm{LXA}_{4}\right)$ is an endogenous pro-resolving mediator for mucosal inflammation that decreases allergic and asthmatic responses. Lipoxin $\mathrm{B}_{4}\left(\mathrm{LXB}_{4}\right)$ is a structurally distinct member of the lipoxin family that signals in a manner distinct from $\mathrm{LXA}_{4}$. $\mathrm{LXB}_{4}$ is generated by mucosal tissues, but its actions in allergic inflammation are unknown. Here, we used murine models of $A R$ and asthma to investigate LXB $_{4}$ 's activity in mucosal inflammation. In the upper airway, $\mathrm{LXB}_{4}$ significantly decreased nasal mucosal leukocytes and degranulation of mast cells (MCs) and eosinophils. In the lower airway, $\mathrm{LXB}_{4}$ significantly decreased airway inflammation, mucus metaplasia, and hyper-responsiveness. Inhibition of $\mathrm{MC}$ degranulation in vivo by $\mathrm{LXB}_{4}$ was more potent than dexamethasone, and these agents displayed unique profiles for cytokine regulation; however, their overall anti-inflammatory actions were comparable. LXB decreased eotaxin-dependent eosinophil chemotaxis, IgE-mediated MC degranulation, and expression of type 2 cytokine receptors. Together, these findings indicate that $\mathrm{LXB}_{4}$ carries cell type selective and mucosal protective actions that broaden the lipoxin family's therapeutic potential for upper and lower airway catabasis.

\section{INTRODUCTION}

Allergic airway diseases, such as rhinitis and asthma, are common and adversely impact patients' function and quality of life. ${ }^{1,2}$ Allergic rhinitis (AR) and atopic asthma can present with chronic mucosal inflammatory processes, and have been referred to as a "united airways" disease. ${ }^{3,4}$ Despite distinct clinical manifestations, these diseases have immunological similarities. For example, eosinophil tissue infiltration and IgEmediated mast cell (MC) activation through FceRI bound allergen are major factors in the pathogenesis of AR and atopic asthma. ${ }^{5}$ Current treatments for AR and asthma principally target symptom relief and anti-inflammation with glucocorticosteroids (GC). Since GC are associated with heterogeneous therapeutic responses and can have serious side effects, there is still a need for new treatment strategies to control AR and asthma. Importantly, no curative therapy is available to resolve allergic airway inflammation.
Recently, research focused on the physiological termination of inflammatory responses has led to the identification of specialized mediators involved in the natural resolution of inflammation in health, including lipoxins (i.e., lipoxin $\mathrm{A}_{4}$ $\left(\mathrm{LXA}_{4}\right)$ and lipoxin $\left.\mathrm{B}_{4}\left(\mathrm{LXB}_{4}\right)\right)^{6}$. These specialized pro-resolving mediators are lipoxygenase-derived eicosanoids formed from arachidonic acid by transcellular metabolism during cell-cell interactions (reviewed in Levy et al. ${ }^{6}$ ). Lipoxins are generated by the upper respiratory tract, including by nasal polyps, ${ }^{7}$ and are present in nasal lavage fluids from aspirinchallenged patients with aspirin-exacerbated respiratory disease. ${ }^{8}$ Lipoxins are also present in the lower airways in broncho-alveolar lavage fluid (BALF) from patients with asthma. ${ }^{9}$ Of note, severe asthma is associated with decreased $\mathrm{LXA}_{4}$ generation. ${ }^{9}$ Administration of a stable analog of $\mathrm{LXA}_{4}$ blocks allergic airway inflammation, mucus metaplasia, and hyper-reactivity to methacholine. ${ }^{10} \mathrm{LXA}_{4}$ is a potent inhibitor of granulocyte recruitment

${ }^{1}$ Pharmacology Unit, The Institute for Drug Research, Faculty of Medicine, The Hebrew University of Jerusalem, Jerusalem, Israel and ${ }^{2}$ Pulmonary and Critical Care Medicine Division, Department of Internal Medicine, Brigham and Women's Hospital, Harvard Medical School, Boston, Massachusetts, USA. Correspondence: BD Levy or F LeviSchaffer (blevy@partners.org or Francescal@ekmd.huji.ac.il)

${ }^{3}$ These authors contributed equally to this work.

Received 25 March 2014; accepted 19 October 2014; published online 3 December 2014. doi:10.1038/mi.2014.116 
and activation, including eosinophils. ${ }^{10} \mathrm{LXB}_{4}$ is a structurally distinct product of arachidonic acid metabolism. $\mathrm{LXB}_{4}$ regulates neutrophil activation; ${ }^{11}$ however, its actions in allergic inflammation and on the functional responses of mucosal effector cells (i.e., $\mathrm{MC}$ and eosinophils), have yet to be established. Here, we provide the first evidence that $\mathrm{LXB}_{4}$ mediates anti-inflammatory and proresolving actions for allergic airway responses in murine models of upper and lower airway mucosal inflammation.

\section{RESULTS}

$L_{X B}$ reduces leukocyte infiltration and mucus secretion in the nasal mucosa

Mice $(B A L B / c)$ were systemically sensitized with ovalbumin (OVA)/aluminum hydroxide (Alum) and then challenged with OVA intranasally to target the allergic responses to the nasal mucosa (Figure 1a, see Methods). Twenty-four hours after the last nasal allergen challenge, mice were given $\mathrm{LXB}_{4}$ (as validated in Supplementary Figure S1 online) (100 ng, intravenous (IV)), dexamethasone (100 ng), or vehicle control for 3 consecutive days (protocol days 28, 29, and 30) (Figure 1a). Mice were killed $24 \mathrm{~h}$ later (protocol day 31). Histopathological assessment of the nasal cavity in mice exposed to vehicle revealed mucosal allergic inflammation with mucin secretion and leukocyte infiltration (Figure 1b). Relative to vehicle, $\mathrm{LXB}_{4}$ reduced inflammatory infiltrates and mucin secretion in the lumen (Figure 1c). Equivalent amounts of dexamethasone also decreased the mucosal inflammation, but to a lesser degree than $\mathrm{LXB}_{4}$ (Figure 1d). BALF that was collected from these mice at the time of nasal tissue excision did not reveal significant increases in eosinophils or other leukocytes (data not shown).

\section{$\mathrm{LXB}_{4}$ has pro-resolving actions on select nasal mucosa cell populations}

Leukocyte infiltration and total nasal mucosal cell numbers were significantly decreased by $\mathrm{LXB}_{4}$ compared with vehicle (Figure 2a). Differential cell count performed on WrightGiemsa stained cytospins of nasal mucosa cells indicated a significant decrease in eosinophils numbers with $\mathrm{LXB}_{4}$ and dexamethasone (Figure $\mathbf{2 b}$ ). The numbers of MC still containing granules significantly increased with $\mathrm{LXB}_{4}$ while dexamethasone gave no significant changes from vehicle (Figure 2c).

MC and eosinophil degranulation is decreased by LXB $_{4}$ Examination of the cytospins following Wright-Giemsa staining revealed striking evidence of changes in leukocyte granule contents (Figure 3). Mice (BALB/c) exposed to vehicle had highly degranulated eosinophils and $\mathrm{MC}$ with evidence for released MC granules (Figure 3a). In sharp contrast, nasal mucosal MC from $\mathrm{LXB}_{4}$-treated mice were larger and retained most of their granule contents, indicative of a less activated state (Figure 3b). Eosinophils also appeared to be less degranulated (Figure 3b). Nasal mucosal MC following dexamethasone treatment showed cellular changes consistent with partial activation and degranulation with cells generally smaller in size than with $\mathrm{LXB}_{4}$ (Figure 3c). Next, the apparent decrease in eosinophils number and degranulation was validated by flow-cytometry analysis where Siglec- $\mathrm{F}^{+}$cells (Supplementary
Figure S2a) and CD107a ${ }^{+}$cells (Supplementary Figure S2b) were significantly decreased by $\mathrm{LXB}_{4}\left(3.50 \pm 0.87\right.$ Siglec- $\mathrm{F}^{+}$

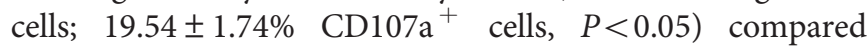
with vehicle $\left(8.51 \pm 1.86 \%\right.$ Siglec- $\mathrm{F}^{+}$cells; $27.15 \pm 1.706 \%$

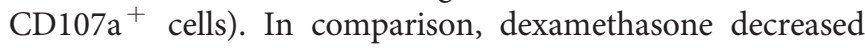
Siglec-F expressing cells $(4.59 \pm 0.79 \%, P<0.05$, Supplementary Figure S2a), but had no significant effect on cell degranulation $\left(\mathrm{CD}_{107 \mathrm{a}^{+}}, P=0.531\right.$, Supplementary Figure S2b).

\section{$\mathrm{LXB}_{4}$ decreases serum OVA-specific IgE levels and select} cytokines/chemokines

Serum titers of OVA-specific IgE (BALB/c mice) were significantly decreased with $\mathrm{LXB}_{4}\left(0.57 \pm 0.10 \mathrm{pg} \mathrm{ml}^{-1}, P<0.01\right)$ and dexamethasone $\left(0.56 \pm 0.08 \mathrm{pg} \mathrm{ml}^{-1}, P<0.01\right)$ relative to vehicle $\left(1.54 \pm 0.29 \mathrm{pg} \mathrm{ml}^{-1}\right)$ (Figure 4a). Additionally, $\mathrm{LXB}_{4}$ significantly decreased serum levels of several mediators associated with IgE production and allergic responses (Figure $\mathbf{4 b}-\mathbf{l}$ ), including IL-4 (Figure 4b; $P<0.05$ ), IL-9 (Figure $4 \mathbf{4 c}$; $P<0.05$ ), RANTES (CCL5) (Figure 4d; $P=0.011$ ), granulocyte macrophage colony-stimulating factor (GM-CSF; Figure 4e; $P<0.01$ ), vascular endothelial growth factor (Figure 4f; $P=0.018$ ), and IL-12 (Figure $4 \mathbf{h} ; P<0.01$ ). Monocyte chemoattractant protein-1 was also decreased by $\mathrm{LXB}_{4}$, but did not reach statistical significance with this sample size (Figure 4g; $P=0.053$ ). Dexamethasone did not share $\mathrm{LXB}_{4}$ 's broad immunoregulatory actions at this time point, but did decrease serum IL-4, IL-9, and GM-CSF (Figure $4 \mathbf{b}$, c, and e). Of interest, $\mathrm{LXB}_{4}$ gave modest increases in keratinocyte chemoattractant (KC) (Figure 4i; $P<0.01$ ) and IL-13 (Figure 4j, $P<0.05)$ levels. The increased serum KC level was not associated with increased tissue neutrophils in the nasal mucosa. Levels of IL- 5 were not significantly influenced by either $\mathrm{LXB}_{4}$ or dexamethasone (Figure 4k). Serum levels of IL-17 were also detected and significantly downregulated by $\mathrm{LXB}_{4}$ (Figure $4 \mathbf{l}$, $P<0.01$ ), but not by dexamethasone (Figure $4 \mathbf{l}$ ).

\section{$\mathrm{LXB}_{4}$ decreases bone marrow-derived MC degranulation and bone marrow-derived eosinophil chemotaxis}

To quantitatively determine whether $\mathrm{LXB}_{4}$ carried direct actions for cell functional responses, IgE-sensitized bone marrow (BM)-derived $\mathrm{MC}$ (BMMC) from naive mice were exposed to $\mathrm{LXB}_{4}$ and compared with $\mathrm{LXA}_{4}$, dexamethasone, or vehicle. Cell activation for degranulation was initiated in a non-antigen-specific manner with an $\operatorname{IgG}(\mathrm{Fab}) 2^{\prime}$ antibody as in Lu-Kuo et al., ${ }^{12}$ see Methods. BMMC degranulation, monitored by the percentage of $\beta$-hexosaminidase release, was significantly decreased with $\mathrm{LXB}_{4}(19.90 \pm 0.86 \%$ of total release relative to vehicle control cells: $39.11 \pm 0.83 \%, P<0.0001$ ) (Figure 5a). $\mathrm{LXA}_{4}$ also decreased BMMC degranulation to $23.97 \pm 1.64 \%$ of total release $(P<0.01)$, and dexamethasone $(10-1,000 \mathrm{nM})$ exhibited concentration-dependent inhibition of BMMC degranulation that relative to vehicle (38.07 \pm 0.4917) was similar in magnitude to $\mathrm{LXB}_{4}$ (100 nM dexamethasone: $33.93 \pm 0.5301, P<0.01 ; 1,000 \mathrm{~nm}$ dexamethasone: $27.05 \pm 0.3910, P<0.0001$ ) (Figure 5b). To determine whether these cellular responses were strain specific, $\mathrm{BALB} / \mathrm{c}$ and FVB cell responses were determined. Both BALB/c (Supplementary 

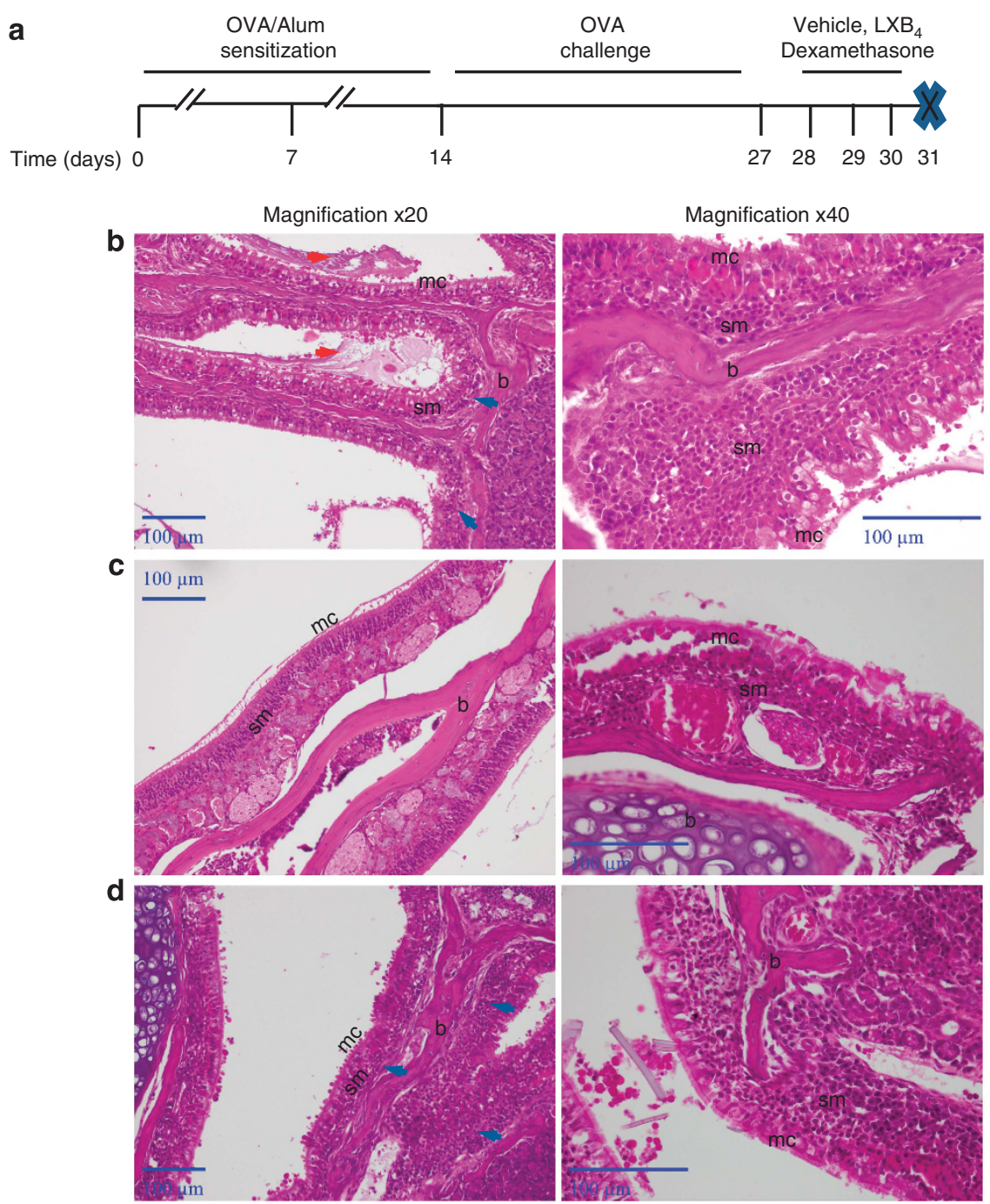

Figure 1 Lipoxin $\mathrm{B}_{4}\left(\mathrm{LXB}_{4}\right)$ reduces leukocyte infiltration and mucus secretion in the nasal mucosa. (a) Days 0 and 7: ovalbumin (OVA)/aluminum

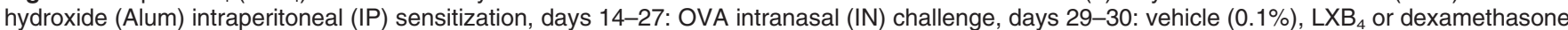
$(100 \mathrm{ng}$ ) intravenous (IV) injection, day 30: sacrifice. (b-d) Hematoxylin and eosin (H\&E)-stained mucosal sections of BALB/c mice injected with vehicle (b), $\mathrm{LXB}_{4}$ (c), or dexamethasone (d). Red arrows-mucus; blue arrows-leukocyte infiltration sm—submucosa; mc-mucosa; b-bone ( $\times 20$ magnification-left panel; $\times 40$ magnification-right panel).

Figure S3a and b) and FVB-derived (Supplementary Figure S3c and d) BMMC responded similarly to IgEmediated activation and degranulation, which was inhibited by $\mathrm{LXB}_{4}$ and $\mathrm{LXA}_{4}$ in a concentration-dependent manner. For eosinophil responses, murine BM-derived eosinophils were exposed to $\mathrm{LXB}_{4}$, and for comparison $\mathrm{LXA}_{4}$ or vehicle, before eotaxin exposure, to determine their impact on chemotaxis (see Methods). Relative to vehicle, $\mathrm{LXB}_{4}$ and $\mathrm{LXA}_{4}$ significantly decreased eotaxin-mediated chemotaxis (Figure 5c).

\section{$\mathrm{LXB}_{4}$ and $\mathrm{LXA}_{4}$ decrease cytokine release from BMMC following IgE-mediated activation}

On the basis of the serum cytokine regulation of AR mice by $\mathrm{LXB}_{4}$, the direct actions of lipoxins on BMMC cytokine release were next determined. BMMC were exposed to $\mathrm{LXB}_{4}, \mathrm{LXA}_{4}$, or vehicle before activation. After $18 \mathrm{~h}$, IgE-mediated activation of BMMC led to a significant TNF- $\alpha$ release that was significantly inhibited by $\mathrm{LXB}_{4}$ and $\mathrm{LXA}_{4}$ in a concentration-dependent manner (Figure 6a-d). $\mathrm{LXB}_{4}$ also decreased FCERI expression (Supplementary Figure S4a and b) without affecting cell viability (Supplementary Figure S4c).

\section{$\mathrm{LXB}_{4}$ regulates allergic lung inflammation}

To determine whether the actions of $\mathrm{LXB}_{4}$ in the lower airways were similar to the upper airways, we first investigated the antiinflammatory activity of $\mathrm{LXB}_{4}$ (Figure 7I, Prevention). OVA sensitized animals (FVB) received $\mathrm{LXB}_{4}$ (100 ng, 1,000 ng) or vehicle (IV) $30 \mathrm{~min}$ before OVA aerosol challenge on protocol days $14-17$ and were then killed $24 \mathrm{~h}$ later on day $18-$ a time of peak allergic inflammation. $\mathrm{LXB}_{4}$ led to a significant 

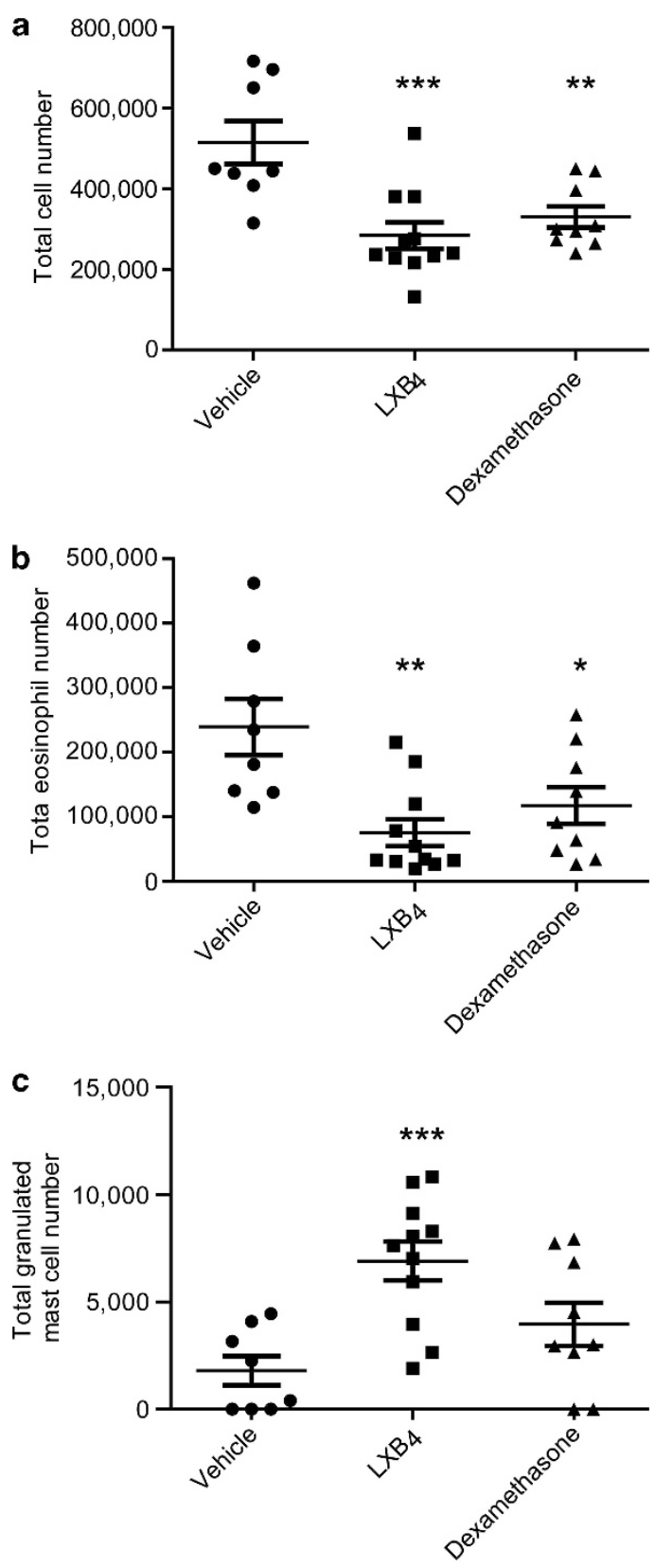

Figure 2 Lipoxin $B_{4}\left(L B_{4}\right)$ has pro-resolving effects on select nasal mucosa cell populations. (a) Total cell number as evaluated in trypan blue exclusion test. (b and $\mathbf{c}$ ) Differential counts of eosinophils (b) and granulated mast cells (c) in stained cytospins from BALB/c mice $(n \geq 8)$, ${ }^{\star} P<0.05,{ }^{* \star} P<0.01,{ }^{* \star} P<0.001$.

dose-dependent decrease in total BALF cell numbers (Figure 7Ia), BALF eosinophils (Figure 7Ib), and BALF lymphocyte numbers (Figure 7Id) but no significant change in macrophage numbers was seen (Figure 7Ic).

Given these anti-inflammatory actions, $\mathrm{LXB}_{4}$ 's pro-resolving actions in the lower airways were next determined by administration after the allergic airways responses were fully established (Figure 7II, Treatment). Twenty-four hours after the last OVA aerosol challenge, $\mathrm{LXB}_{4}(100 \mathrm{ng}$, IV) was given (protocol day 18) and repeated on days 19 and 20. Mice were killed $24 \mathrm{~h}$ later (day 21) during the resolution phase of this model. Relative to vehicle, $\mathrm{LXB}_{4}$ significantly accelerated the resolution of the allergic lung inflammation with decreased BALF total cell number (Figure 7IIe) and decreased eosinophils, macrophage and lymphocyte numbers (Figure 7IIf-h). The resolution interval $\left(R_{\mathrm{i}}\right)$ was calculated for BALF total cells ( $\sim 6$ days with vehicle) and $\mathrm{LXB}_{4}$ shortened the $R_{\mathrm{i}}$ by over $30 \%$ to $\sim 4$ days (Figure 7IIi).

\section{$\mathrm{LXB}_{4}$ promotes the resolution of airway hyper-responsiveness and lung inflammation}

In addition to airway inflammation, airway hyper-responsiveness (AHR) is a clinical hallmark of asthma; ${ }^{1}$ therefore, the impact of $\mathrm{LXB}_{4}$ on methacholine-triggered increases in lung resistance was determined. Relative to vehicle, mice (FVB) exposed to $100 \mathrm{ng} \mathrm{LXB}_{4}$ treatment (as in Figure 7II) had significantly less AHR to methacholine (Figure 8a). In addition, histological analysis of lung sections from animals not subjected to AHR testing revealed that $\mathrm{LXB}_{4}$ led to significant reductions in leukocyte infiltration and epithelial cell activation (Figure 8b, c). Mice treated with $\mathrm{LXB}_{4}(100 \mathrm{ng}$ ) also exhibited a faster resolution of mucus metaplasia, as evidenced by decreased Periodic Acid Schiff-positive airway epithelial cells compared with vehicle (Figure 8d). A significant decrease in BALF Th2 cytokines (Figure 8e-g) was observed, particularly for IL-4 (Figure 8e, vehicle: $27.68 \pm 12.98$; $\mathrm{LXB}_{4}: 15.51 \pm 7.40, P<0.05$ ) and IL-13 (Figure 8g, vehicle: $\left.3.21 \pm 1.145 ; \mathrm{LXB}_{4}: 0.845 \pm 0.483, P<0.05\right)$. Given the importance of IL-13 signaling in airway mucus metaplasia and airway hyperreactivity to methacholine, ${ }^{13-16}$ we next determined the influence of $\mathrm{LXB}_{4}$ on IL-13 receptors (Figure $\mathbf{8 h}-\mathbf{j}$ ). Lung expression of the shared IL-4 receptor decreased during resolution (day 21) relative to the peak of inflammation (day 18), and $\mathrm{LXB}_{4}$ further accelerated this decrease in lung IL-4 receptor expression (Figure $\mathbf{8 h}$ ). $\mathrm{LXB}_{4}$ administration also markedly decreased the expression of IL-13-specific receptors IL-13R $\alpha 1$ and IL-13R $\alpha 2$ (Figure 8i, $\mathbf{j}$ ).

\section{DISCUSSION}

$\mathrm{AR}$ and asthma are common allergic conditions with high morbidity. Allergen avoidance is often difficult and impractical and there is no curative therapy for the resultant allergic inflammation. Thus, new therapeutic approaches are needed. To this end, $\operatorname{LXB}_{4}\left(\sim 5 \mu \mathrm{g} \mathrm{kg}^{-1}\right)$ displayed pro-resolving actions for allergic mucosal inflammation in murine models of $\mathrm{AR}$ and asthma. $\mathrm{LXB}_{4}$ decreased mucosal leukocyte infiltration, OVA-specific IgE, MC, and eosinophils degranulation, mucus metaplasia, and AHR to methacholine.

$\mathrm{LXB}_{4}$ mediated direct actions on pivotal cellular effectors for allergy, namely MC and eosinophils (as shown on cell functional responses in vitro), as well as indirect actions on these cells (regulation of levels of inflammatory mediators). Distinct from their important role during the induction of allergic airway responses, the levels of type 2 cytokines during resolution and their response to $\mathrm{LXB}_{4}$ varied. In resolving upper and lower airways, $\mathrm{LXB}_{4}$ potently decreased serum IL-4 and IgE 


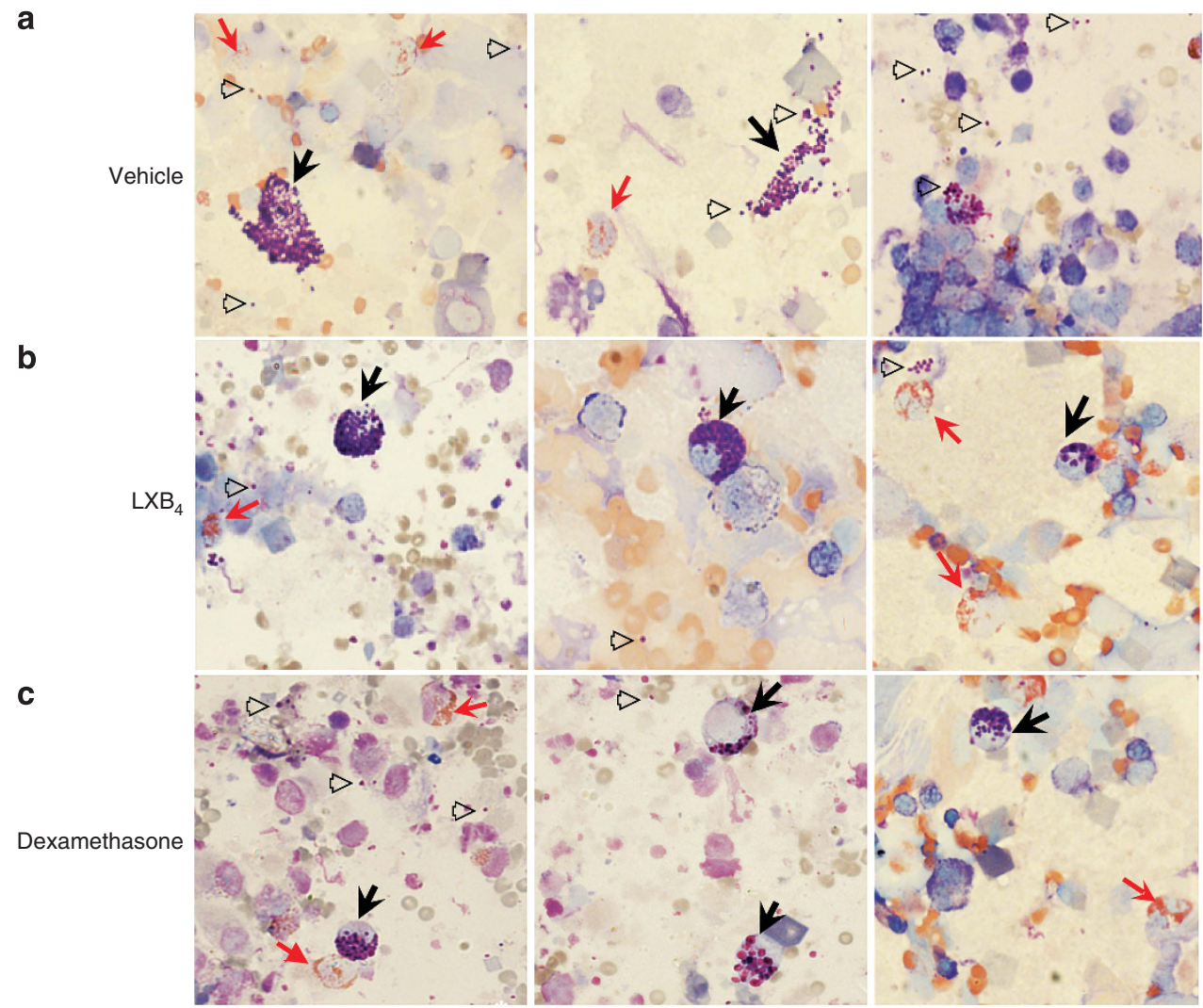

Figure 3 Fewer degranulated mast cells and eosinophils were evident in nasal mucosa with Lipoxin $B_{4}\left(L_{X B}\right)$ treatment. (a-c) Images of WrightGiemsa stained cytospins of vehicle (a), $\mathrm{LXB}_{4}(\mathbf{b})$, and dexamethasone $(\mathbf{c})$ injected BALB/c mice $(\times 40)$. Representative images from three mice. Black arrows-mast cells; hollow arrowheads-mast cell granules; and red arrows-eosinophils.

levels. Because significant changes were not present in IL-5 levels, $\mathrm{LXB}_{4}$ regulation of eosinophils function appears to have resulted from a direct action on these cells as well as from the reduced levels of GM-CSF. Surprisingly, $\mathrm{LXB}_{4}$ increased serum IL-13 as the upper airways resolved. In contrast, BALF IL-13 was decreased by $\mathrm{LXB}_{4}$, suggesting local and distinct regulatory mechanisms. Although IL-13 can initiate allergic inflammation, it can also have a role in limiting inflammation. Of note, IL-13 has the capacity to induce the expression of 15lipoxygenase, which catalyzes the formation of both $\mathrm{LXB}_{4}$ and $\mathrm{LXA}_{4}{ }^{6}$

IL-4 has important roles in isotype switching and $\operatorname{IgE}$ production, ${ }^{17,18}$ and $\mathrm{LXB}_{4}$ inhibited both IL-4 and serum IgE levels. Given the differential actions on IL-13 levels, expression of its receptors was determined. Lung expression of IL-4R, IL-13R $\alpha 1$, and IL-13R $\alpha 2$ was downregulated during resolution and further decreased by $\mathrm{LXB}_{4}$. IL-4R-deficient mice display weak Th2 responses. ${ }^{19}$ IL-13R $\alpha 1$ deficiency has an established role in allergic airway responses. ${ }^{20}$ Thus, $\mathrm{LXB}_{4}$ regulation of IL-4R and IL-13R $\alpha 1$ expression would serve to decrease mucus metaplasia and airway hyper-reactivity. No $\mathrm{LXB}_{4}$-mediated increases in expression of the IL-13 decoy receptor IL-13R $\alpha 2$ were apparent. In asthma, regulation of IgE and IL-13 has beneficial actions in some asthmatic patients, ${ }^{21,22}$ so together these findings suggest therapeutic potential for $\mathrm{LXB}_{4}$ or its stable analogs. ${ }^{23}$
The increase in serum $\mathrm{KC}$ with $\mathrm{LXB}_{4}$ was unexpected and distinct from $\mathrm{LXA}_{4}{ }^{24}$ In addition to its well-defined role as a neutrophil chemoattractant, $\mathrm{KC}$ can modulate ciliary function of murine sinonasal epithelial cells, ${ }^{25,26}$ suggesting that $\mathrm{LXB}_{4}$ might enhance mucociliary clearance via this mechanism. In contrast to KC, serum IL-17 levels were low and significantly decreased by $\mathrm{LXB}_{4}$. Compared with the GC dexamethasone, $\mathrm{LXB}_{4}$ 's actions were of similar potency for decreasing inflammatory cell activation and more potent for regulating degranulation in vivo. Although consistently decreased by $\mathrm{LXB}_{4}$, there was donor-to-donor variability for the magnitude of stimulusdriven BMMC degranulation, suggesting context-dependent responses for $\mathrm{MC}$ and their regulation by $\mathrm{LXB}_{4}$. Direct cellular actions for $\mathrm{LXB}_{4}$ were also identified in vitro for inhibition of BMMC TNF- $\alpha$ production and BM-derived eosinophil chemotaxis. Together, these lines of evidence support potent antiallergic and pro-resolving actions for $\mathrm{LXB}_{4}$ on $\mathrm{MC}$ and eosinophils that were relevant for both upper and lower airways.

Notably, $\mathrm{LXA}_{4}$ blocks histamine release from MC during interactions with epithelial cells ${ }^{27}$ and decreases neutrophil degranulation of azurophilic granules. ${ }^{28}$ In conjunction with $\mathrm{LXB}_{4}$ 's actions here in vitro, the lipoxins $\left(\mathrm{LXA}_{4}\right.$ and $\left.\mathrm{LXB}_{4}\right)$ carry $\mathrm{MC}$ and granulocyte stabilizing activity. Apart from its direct regulation of $\mathrm{MC}$ and eosinophils, $\mathrm{LXB}_{4}$ blocks T-cell activation, cytokine release, ${ }^{29}$ and neutrophil chemotaxis. ${ }^{11}$ Indirect mechanisms are also likely in the accelerated resolution 

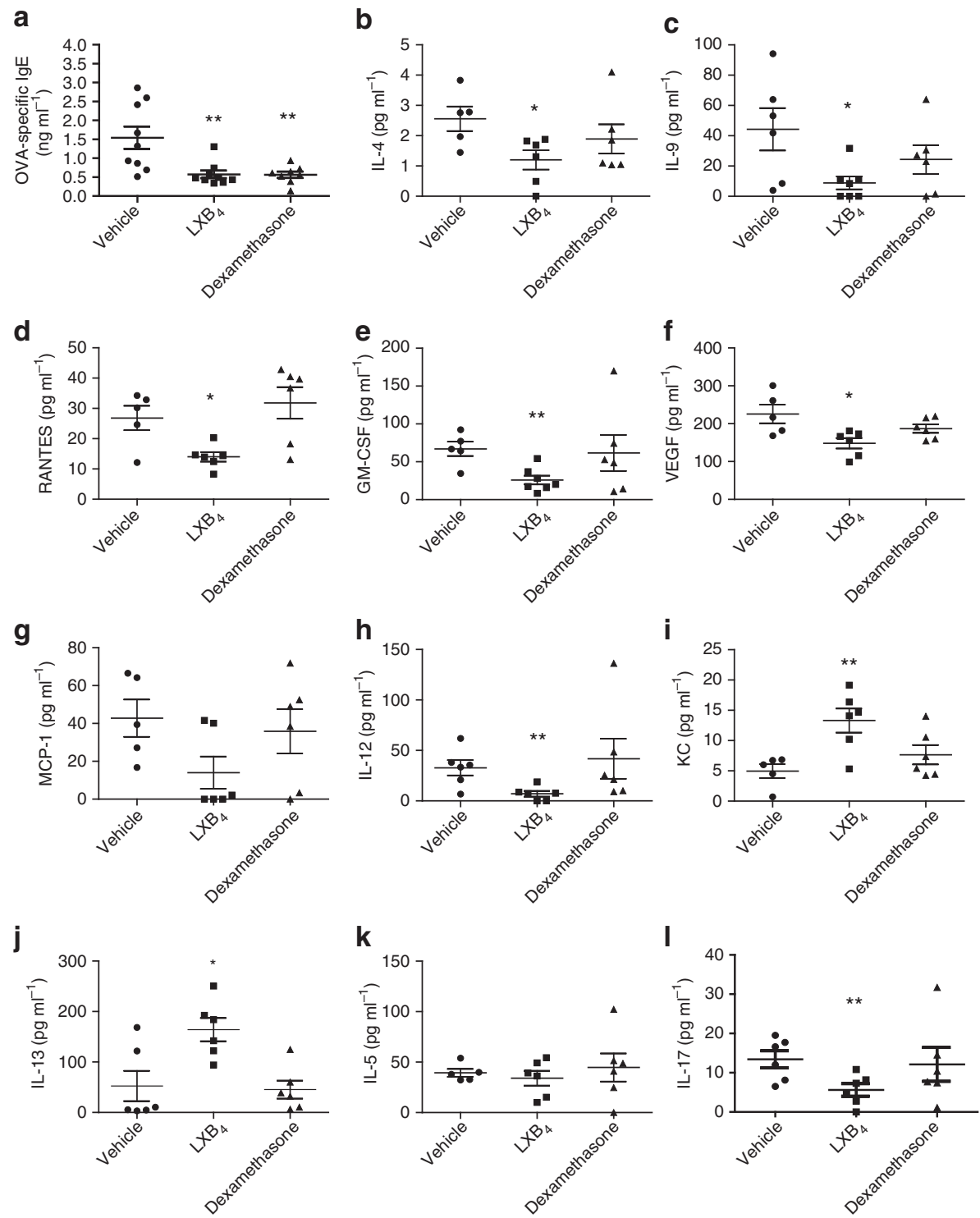

Figure 4 Lipoxin $B_{4}\left(L X B_{4}\right)$ decreases ovalbumin (OVA)-specific IgE levels and modulates various cytokines in serum of allergic rhinitis (AR) mice. (a) OVA-specific IgE levels in vehicle, $\mathrm{LXB}_{4}$, and dexamethasone injected BALB/c mice $(n=9)$. (b-I) Cytokine expression in serum of vehicle, LXB ${ }_{4}$, and dexamethasone injected mice $(n \geq 5)$, ${ }^{\star} P<0.05 ;{ }^{\star *} P<0.01$ two-tailed Student's $t$-test.

of allergic lung inflammation, as levels of several inflammatory mediators, including GM-CSF, a pro-survival cytokine for eosinophils, were decreased by $\mathrm{LXB}_{4}$. Of interest, $\mathrm{LXA}_{4}$ has a counter-regulatory effect on GM-CSF signaling in a human eosinophil cell line (EoL-1) and peripheral blood eosinophils. ${ }^{30}$ $\mathrm{LXA}_{4}$ also inhibits human eosinophils recruitment in vitro ${ }^{31}$ and murine eosinophils in vivo, ${ }^{10}$ and can induce natural killer cells to promote human eosinophils apoptosis in asthma to enhance their non-phlogistic clearance from inflamed tissues. ${ }^{32}$ Together, these findings highlight several cellular mechanisms for lipoxin regulation of allergic airway inflammation.

$\mathrm{LXB}_{4}$ and $\mathrm{LXA}_{4}$ are generated by nasal polyps where a mucosal epithelial 15-lipoxygenase has an important role in their biosynthesis. $\mathrm{LXA}_{4}$ is present in nasal secretions ${ }^{10}$ and airway samples from human asthmatic patients. ${ }^{9,33}$ Eosinophilic donors generate $\mathrm{LXA}_{4}$ preferentially to $\mathrm{LXB}_{4}{ }^{34}$ however, this is cell type specific as human platelet 12-lipoxygenase converts leukotriene $\mathrm{A}_{4}$ into $\mathrm{LXA}_{4}$ and $\mathrm{LXB}_{4}$ in an equimolar ratio, ${ }^{35}$ and IL- 4 exposed alveolar macrophage 15-lipoxygenase generates $\mathrm{LXB}_{4}$ preferentially to $\mathrm{LXA}_{4} \cdot{ }^{36}$ The nanogram doses of $\mathrm{LXB}_{4}$ used here are within physiological concentrations generated during inflammatory responses and were very potent $\left(\sim 5 \mu \mathrm{gg}^{-1}\right)$ in comparison with a similar dose of dexamethasone. $\mathrm{LXA}_{4}$ interacts with several receptors, including the G-protein coupled receptor ALX/FPR2. While $\mathrm{LXB}_{4}$ also displays pharmacological properties of a G-protein coupled receptor agonist, it binds to a receptor distinct from ALX/FPR2 that has yet to be identified.

In conclusion, $\mathrm{LXB}_{4}$ displayed pro-resolving actions for mucosal allergic responses in the upper and lower airways. $\mathrm{LXB}_{4}$ is generated in the airway and the present results are the 

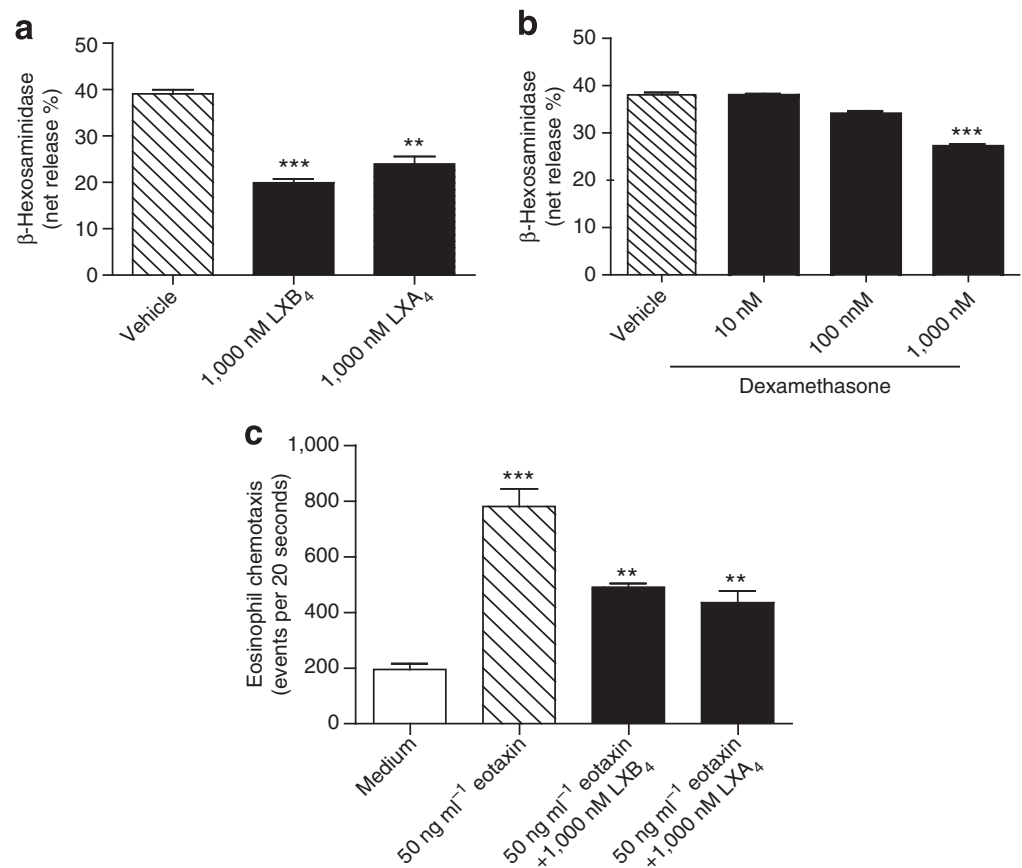

Figure 5 Lipoxin $B_{4}\left(L X B_{4}\right)$ decreases $B M M C$ degranulation and $B M$ eosinophils chemotaxis. Cells were derived from $B A L B / c$ mice $B M$ as described in Methods. ( $\mathbf{a}$ and $\mathbf{b}$ ) BMMC IgE-dependent activation ( $\beta$-hexosaminidase release) (c) BM eosinophil chemotaxis to eotaxin presented as number of events counted per $20 \mathrm{~s}$ in the flow cytometer (see Methods) $(n=3),{ }^{* *} P<0.01,{ }^{* * *} P<0.001$.

a

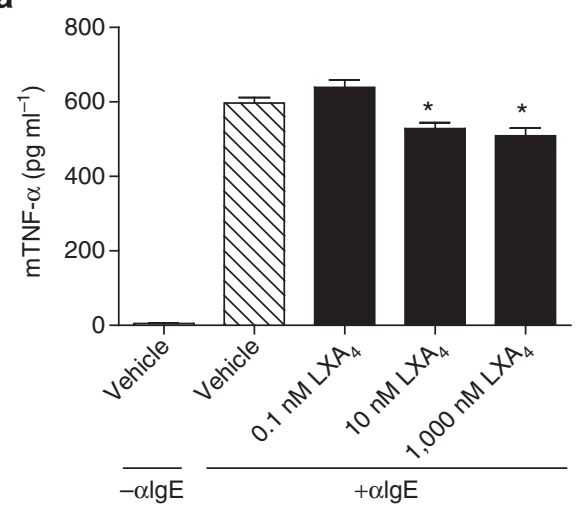

C

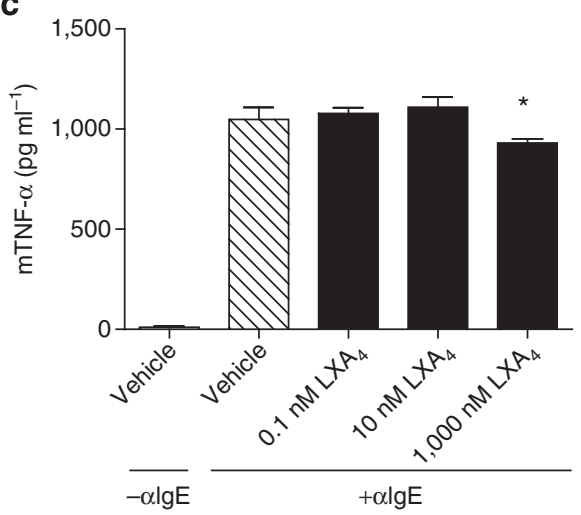

b

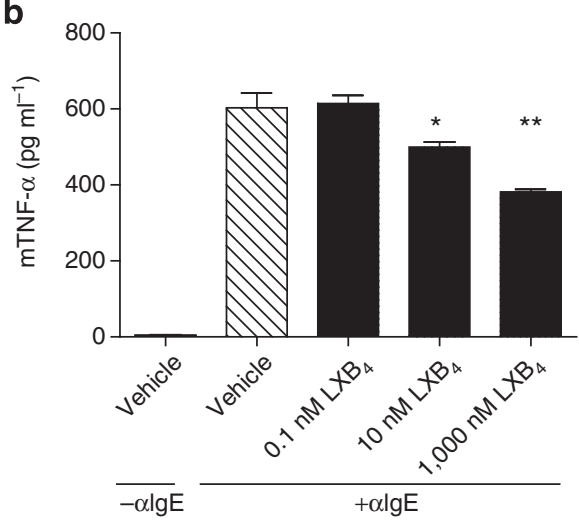

d

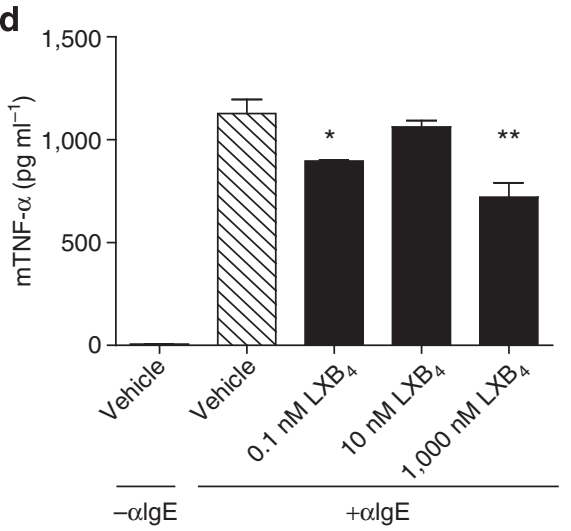

Figure 6 Lipoxin $B_{4}\left(L X B_{4}\right)$ and $L X A_{4}$ decrease TNF- $\alpha$ release from BMMC following IgE-mediated activation. BMMC were derived from $B A L B / c$ and FVB mice BM and treated as described in Methods. IgE activation was carried out with anti-rat lgG (Fab)2 $\left(10 \mu \mathrm{g} \mathrm{ml}^{-1}\right)(\mathbf{a}$ and $\mathbf{b}) \mathrm{TNF}^{\prime}-\alpha$ levels $\left(\mathrm{pg} \mathrm{ml} \mathrm{ml}^{-1}\right)$ in BALB/c cell supernatants following incubation with $\mathrm{LXB}_{4}$ (a) and $\mathrm{LXA}_{4}$ (b). (c and d) TNF- $\alpha$ levels (pg ml ${ }^{-1}$ ) in FVB cell supernatants following incubation with $\mathrm{LXB}_{4}(\mathbf{c})$ and $\mathrm{LXA}_{4}(\mathbf{d}),{ }^{\star} P<0.05,{ }^{\star \star} P<0.01$. 

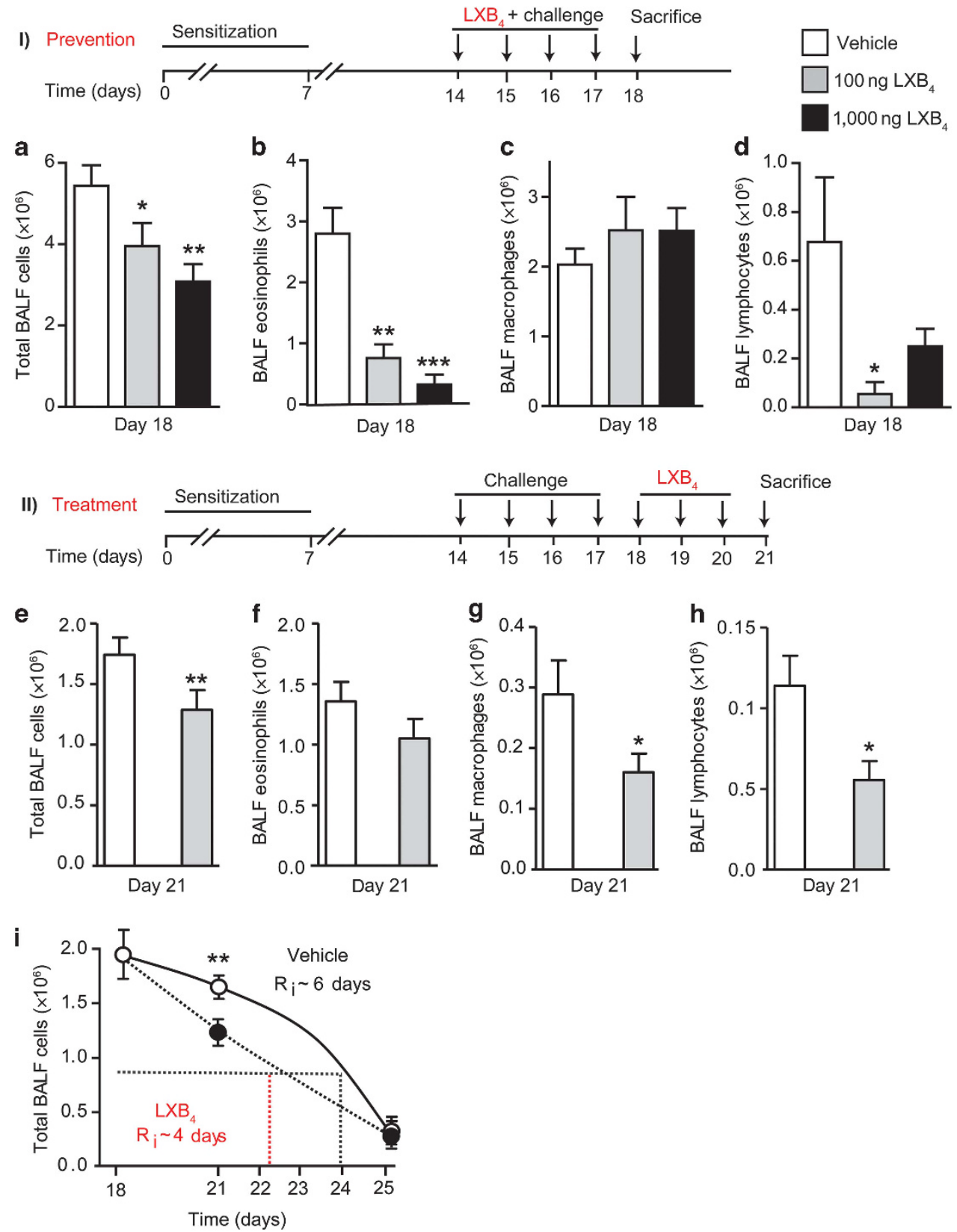

Figure 7 Lipoxin $B_{4}\left(L X B_{4}\right)$ regulates allergic lung inflammation. FVB mice were sensitized and aerosol challenged with ovalbumin (OVA). LXB ${ }_{4}$ (100, $1,000 \mathrm{ng}$ ) or vehicle was injected: (I) Prevention-30 min before challenge (days 14-17). (II) Treatment-after the last challenge (days 18-20). Total cell ( $\mathbf{a}$ and $\mathbf{e})$, eosinophil (b and f), macrophage (c and $\mathbf{g}$ ), and lymphocyte ( $\mathbf{d}$ and $\mathbf{h}$ ) numbers in BALF. The resolution interval- $R_{\mathbf{i}}(\mathbf{i})$ for vehicle/LXB ${ }_{4}$ injected mice $(n \geq 5)$, ${ }^{\star} P<0.05,{ }^{\star \star} P<0.01,{ }^{* \star *} P<0.001$ one-tailed Student's $t$-test.

first demonstration of an airway protective effect for $\mathrm{LXB}_{4}$ or that any specialized pro-resolving mediator is active in the nasal mucosa. With the development of $\mathrm{LXB}_{4}$ stable analogs and the limited treatment options currently available, these findings suggest a potential new pro-resolving therapeutic strategy for allergic conditions.

\section{METHODS}

Materials. $\mathrm{LXA}_{4}$ and $\mathrm{LXB}_{4}$ were from Cayman Chemical (Ann Arbor, $\mathrm{MI}$ ) and dexamethasone was from MP Biomedicals LLC (Solon, OH). The lipoxins were stored at $-80^{\circ} \mathrm{C}$ under a blanket of $\mathrm{N}_{2}$ and their integrity was monitored by UV-vis spectrophotometry and HPLC (Supplementary Figure S1).

Allergic upper and lower airway models. The allergic upper airway model was designed to reflect $\mathrm{AR}$ and was a modification of a previously published protocol ${ }^{37}$ (Figure 1). Briefly, BALB/c female mice (Harlan Laboratories, Jerusalem, Israel), aged 7-8 weeks (20$23 \mathrm{~g}$ ) were sensitized on day 0 and day 7 by intraperitoneal injection of $200 \mu \mathrm{l}$ chicken ovalbumin (OVA; $1 \mathrm{mg} \mathrm{ml}^{-1}$ ) (Amresco, OH) and aluminum hydroxide (alum; $50 \mathrm{mg} \mathrm{ml}^{-1}$ ) (Acros Organics, Morris Plains, NJ) in phosphate-buffered saline (PBS). Starting on day 14, awake mice were challenged twice a day by intranasal (IN) instillation of $20 \mu \mathrm{l} \mathrm{OVA}\left(25 \mathrm{mg} \mathrm{ml}^{-1}\right)$ daily until day 27 . For the allergic lower 
a

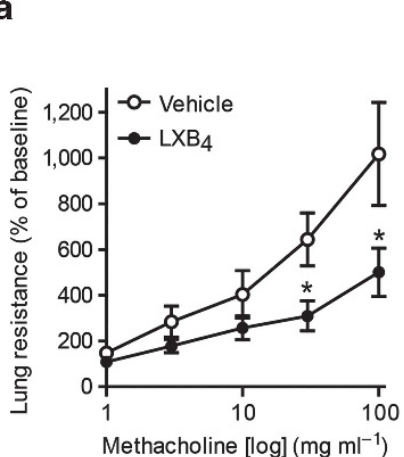

\section{b}
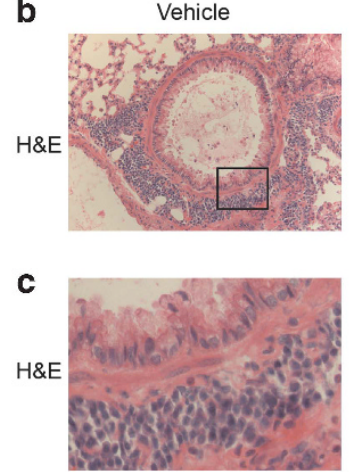

d

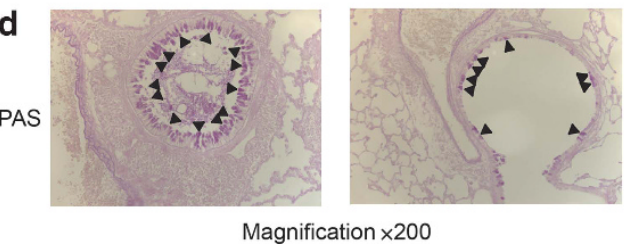

e
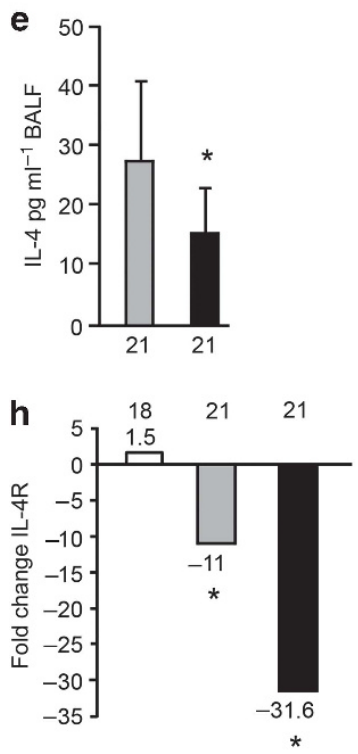

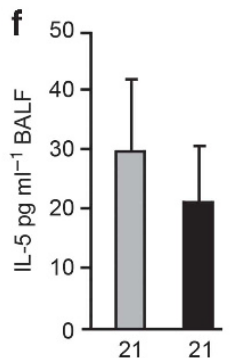

i

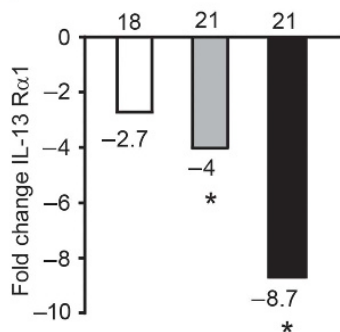

g

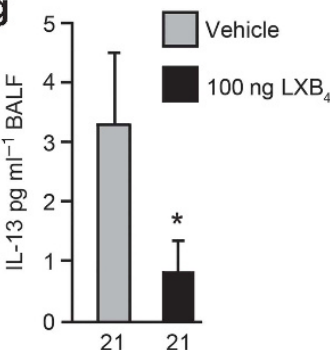

j

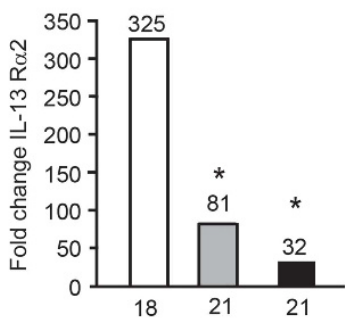

Figure 8 Lipoxin $B_{4}\left(L_{X B}\right)$ promotes the resolution of airway hyper-responsiveness and lung inflammation. (a) Determination of airway hyperresponsiveness to metacholine, $(n \geq 5),{ }^{*} P<0.05$ one-tailed Student's $t$-test (b and $\mathbf{c}$ ) hematoxylin and eosin (H\&E) and (d) Periodic Acid Schiff (PAS) staining of FVB mice lungs. Arrow heads point to mucus (magenta positive) Goblet cells $(\times 20)$. $(\mathbf{e}-\mathbf{g})$ IL-4, IL-5, and IL-13 cytokine levels in BALF, ( $n \geq 5$ ) ${ }^{\star} P<0.05$ paired Student's $t$-test. $(\mathbf{h}-\mathbf{j})$ mRNA levels of lung IL-4R, IL-13R $\alpha 1$, and IL-13R $\alpha 2(n \geq 5){ }^{*} P<0.05$.

airway model, a previously published protocol with OVA was used to reflect atopic asthma. ${ }^{38}$ Briefly, FVB male mice aged 5-7 weeks (Charles River Laboratories) were housed in isolation cages under viral antibody-free conditions. Mice were fed a standard diet (Laboratory Rodent Diet 5001, PMI Nutrition International, St. Louis, MO). Mice were sensitized with intraperitoneal injections of OVA $(10 \mu \mathrm{g})$ and $1 \mathrm{mg}$ alum in $0.2 \mathrm{ml}$ saline on days 0 and 7 . Mice were then challenged on days $14-17$ with an aerosol of 6\% OVA (25 min).

Treatment protocols. Mice were given intravenous (IV) $\mathrm{LXB}_{4}(100$ or $1,000 \mathrm{ng})$, vehicle $(0.1 \%$ ethanol), or dexamethasone (100 ng). To determine pro-resolving actions, treatments were given after the completion of allergen challenge at peak allergic airway inflammation time: days 28, 29, and 30 in the upper airway model (Figure 1a) or days 18,19 , and 20 in the lower airway model (Figure 7II). Calculation of the resolution interval $\left(R_{\mathrm{i}}\right)$ (i.e., time interval for the maximum number of cells to decrease by $50 \%$ ) was then evaluated as in Bannenberg et al. ${ }^{39}$ To determine anti-inflammatory actions, $\mathrm{LXB}_{4}(100 \mathrm{ng})$ or vehicle was given IV on protocol days 14, 15, 16, and 17, $30 \mathrm{~min}$ before OVA aerosol challenge (Figure 7I). Twenty-four hours after the last IV treatment, mice were euthanized for the collection of airway and systemic specimens. Mouse experiments were approved by the Animal Ethics committee, The Hebrew University, Jerusalem, Israel, and the Harvard Medical Area IRB, Boston, MA (Protocol \#03618).

Nasal tissue preparation of cell suspensions and histopathology. As in Miyahara et al., ${ }^{37}$ extensive dissection was required to obtain the nasal mucosa cell suspensions (see Supplementary Methods in the Online Data Supplement). Total viable cell numbers were enumerated 
by Trypan blue exclusion. Nasal tissue sections were prepared and stained for hematoxylin and eosin.

Flow cytometry. Single-cell suspensions from nasal mucosa were resuspended in $\mathrm{PBS} / 0.1 \%$ bovine serum albumin seeded in a 96-well plate at $10^{6}$ cells per $\mathrm{ml}$, blocked with $5 \%$ goat serum and stained with Phycoerythrin-conjugated anti-CD107a (eBioscience, San Diego, CA) and anti-Siglec-F (BD Biosciences, San Jose, CA) for the detection of total degranulation ${ }^{40}$ and eosinophils, respectively. For in vitro assessment of BMMC expression of FCeRI, cells were stained with anti-FCeRI (eBioscience) and cell viability was determined by propidium iodide staining (Sigma-Aldrich, Rehovot, Israel). Data were analyzed by a FACSCalibur and CellQuest software (Becton Dickinson, San Jose, CA).

$\mathrm{LXA}_{4} / \mathrm{LXB}_{4}$ activity on mouse BMMCs and eosinophils. BMMC and $\mathrm{BM}$ eosinophils were obtained as previously described. ${ }^{41,42}$ BMMC from $\mathrm{BALB} / \mathrm{c}$ and FVB mice $\left(1 \times 10^{6}\right.$ per $\left.\mathrm{ml}\right)$ were sensitized overnight with Rat Myeloma IgE $\left(1 \mu \mathrm{g} \mathrm{ml}^{-1}\right.$; Molecular Probes, Invitrogen, Carlsbad, CA). Cells were washed, resuspended in Tyrode's buffer and pre-incubated in a 96-well plate $\left(2 \times 10^{5}\right.$ per well $)$ with $\mathrm{LXB}_{4}$, $\mathrm{LXA}_{4}$, or vehicle at the indicated concentrations for $30 \mathrm{~min}$ at $37^{\circ} \mathrm{C}$. Cells were then activated by the addition of a goat anti-rat IgG (Fab) $2^{\prime}$ antibody $\left(10 \mu \mathrm{g} \mathrm{ml}^{-1}\right)$ (Jackson ImmunoResearch Laboratories, Inc., West Grove, PA) $\left(30 \mathrm{~min}, 37^{\circ} \mathrm{C}\right)$ in Tyrode's buffer. Degranulation was evaluated by a colorimetric enzymatic $\beta$-hexosaminidase release assay. ${ }^{43}$ For TNF- $\alpha$ release, supernatants were collected $18 \mathrm{~h}$ following BMMC activation for evaluation of mTNF- $\alpha$ quantified by ELISA (Peprotech Asia, Israel). For chemotaxis, BM eosinophils were similarly pre-treated and then seeded into the upper chamber of a 24 transwell plate $\left(2 \times 10^{5}\right.$ per well per $100 \mu$ l) (Corning, Tewksbury, MA) with a $5.0-\mu \mathrm{m}$ pore size polycarbonate membrane. Cells were incubated $\left(37^{\circ} \mathrm{C}, 3 \mathrm{~h}\right)$ to allow migration across the membrane in response to medium only or medium with murine eotaxin (R\&D Biosystems, Minneapolis, MN) in the lower wells $\left(50 \mathrm{ng} \mathrm{ml}^{-1}\right.$ per $600 \mu \mathrm{l})$. Migrated BM eosinophils were assessed by aspirating a fixed volume from the lower wells and counting the cells by flow cytometer (20 s, duplicate determinations).

Cytospin preparation. Nasal mucosa and BALF cells were resuspended in $\mathrm{PBS} / 2 \%$ bovine serum albumin, enumerated by a hemacytometer and cytocentrifuged (1,000 r.p.m., 4 min, r.t.) followed by staining with Modified Wright-Giemsa (Sigma-Aldrich). Total cells, $\mathrm{MC}$, and eosinophil numbers were counted.

Evaluation of serum cytokines/chemokines and OVA-specific IgE levels. Blood samples were collected from the inferior vena cava and sera were stored $\left(-80^{\circ} \mathrm{C}\right)$ until measurement of OVA-specific IgE levels by ELISA (Uscn Life Science Inc., Wuhan, China) and select cytokines/chemokines with Quantibody Mouse cytokine array 1 (Ray Biotech, Norcross, GA).

BALF and lung sample preparation and evaluation. Bronchoalveolar lavage was performed with $2 \times 1 \mathrm{ml}$ aliquots of PBS with $0.6 \mathrm{~mm}$ EDTA. Lungs were fixed at $25 \mathrm{~cm} \mathrm{H}_{2} \mathrm{O}$ in $10 \%$ buffered formalin and paraffin embedded for hematoxylin and eosin and Periodic Acid Schiff staining (Sigma-Aldrich, St. Louis, MO). Cell-free BALF (centrifuged at $2,000 \mathrm{~g}$ for $10 \mathrm{~min}$ ) was coded and select cytokines/chemokines measured by bead array (Pierce Biotechnology, Rockford, IL).

RNA isolation and real-time PCR. Lungs were obtained and snapfrozen RNA was extracted with TRIzol (Invitrogen) and reverse transcribed. The cDNA was used as a template for the amplification of selected genes. The difference between the $\mathrm{Ct}$ value for the gene of interest and the respective $\mathrm{Ct}$ value for the control gene was then calculated $(\Delta \mathrm{Ct})$. The fold change was calculated as $2^{-\Delta \Delta \mathrm{Ct}}$. Primers were purchased from Invitrogen: mouse IL-13R $\alpha 1$ : right CGTG CAGAGATTTTCGACAG, left AGCTGTTGGTGCTGCTACTG, IL13R $\alpha 2$ : right GGCAAAGAAGTAACAAAAGGAAT, left CGAATG
GAGTGAAGAGGAATG, IL-4R: right AAGCACGCAGATCCAAA ATC, left GTGGAGCCTGAACTCGCA, GAPDH: right TTGATGG CAACAATCTCCAC, left CGTCCCGTAGACAAAATGGT, and $\beta$-actin: right ATGGAGGGGAATACAGCCC, left TTCTTTGCA GCTCCTTCGTT.

Statistical analysis. All parameters were analyzed using the GraphPad Prism 5 software (GraphPad Software, La Jolla, CA). Data are expressed as means \pm s.e.m.'s. Statistical comparisons were performed using one-way ANOVA, followed by the Tukey post test. When only two groups were compared, statistical differences were determined using the unpaired Student's $t$-test. A $P$-value of $<0.05$ was considered as significant.

SUPPLEMENTARY MATERIAL is linked to the online version of the paper at http://www.nature.com/mi

\section{ACKNOWLEDGMENTS}

We acknowledge Professor Charles N. Serhan for helpful discussions on this project and critical appraisal of the manuscript, as well as Nour Karra and Jennifer Colby for assisting with sample preparations. This research was supported in part by the US National Institutes of Health grants Al068084, HL68669, and P01-GM095467 (B.D.L.) and by the Aimwell Charitable Fund, UK (F.L-S).

\section{AUTHOR CONTRIBUTIONS}

L.K. planned and performed experiments, collected and analyzed data, and wrote the manuscript; O.H. planned and performed experiments, collected and analyzed data, and edited the manuscript; R.P. performed experiments, B.D.L. and F.L-S co-designed the study, performed experiments, analyzed data, and wrote the manuscript.

\section{DISCLOSURE}

The authors declared no conflict of interest.

(c) 2015 Society for Mucosal Immunology

\section{REFERENCES}

1. Fanta, C.H. Asthma. N. Engl. J. Med. 360, 1002-1014 (2009).

2. Plaut, M. \& Valentine, M.D. Clinical practice. Allergic rhinitis. N. Engl. J. Med. 353, 1934-1944 (2005).

3. KleinJan, A. et al. United airways: circulating Th2 effector cells in an allergic rhinitis model are responsible for promoting lower airways inflammation. Clin. Exp. Allergy 40, 494-504 (2010).

4. Palm, N.W., Rosenstein, R.K. \& Medzhitov, R. Allergic host defences. Nature 484, 465-472 (2012)

5. Locksley, R.M. Asthma and allergic inflammation. Cell 140, 777-783 (2010).

6. Levy, B.D., Vachier, I. \& Serhan, C.N. Resolution of inflammation in asthma. Clin. Chest. Med. 33, 559-570 (2012).

7. Edenius, C., Kumlin, M., Bjork, T., Anggard, A. \& Lindgren, J.A. Lipoxin formation in human nasal polyps and bronchial tissue. FEBS Lett. 272, 25-28 (1990).

8. Levy, B.D. et al. Agonist-induced lipoxin A4 generation: detection by a novel lipoxin A4-ELISA. Lipids 28, 1047-1053 (1993).

9. Planaguma, A. et al. Airway lipoxin A4 generation and lipoxin A4 receptor expression are decreased in severe asthma. Am. J. Respir. Crit. Care Med. 178, 574-582 (2008)

10. Levy, B.D. et al. Multi-pronged inhibition of airway hyper-responsiveness and inflammation by lipoxin A(4). Nat. Med. 8, 1018-1023 (2002).

11. Lee, T.H. et al. Lipoxin A4 and lipoxin B4 inhibit chemotactic responses of human neutrophils stimulated by leukotriene B4 and N-formyl-L-methionyl-L-leucyl-L-phenylalanine. Clin. Sci. 77, 195-203 (1989).

12. Lu-Kuo, J.M., Joyal, D.M., Austen, K.F. \& Katz, H.R. gp49B1 inhibits IgEinitiated mast cell activation through both immunoreceptor tyrosine-based inhibitory motifs, recruitment of src homology 2 domain-containing phosphatase-1, and suppression of early and late calcium mobilization. J. Biol. Chem. 274, 5791-5796 (1999). 
13. Fallon, P.G., Emson, C.L., Smith, P. \& McKenzie, A.N. IL-13 overexpression predisposes to anaphylaxis following antigen sensitization. J. Immunol. 166, 2712-2716 (2001).

14. Wills-Karp, M. et al. Interleukin-13: central mediator of allergic asthma. Science 282, 2258-2261 (1998).

15. Kuperman, D.A. et al. Direct effects of interleukin-13 on epithelial cells cause airway hyperreactivity and mucus overproduction in asthma. Nat. Med. 8, 885-889 (2002).

16. Zhu, Z. et al. Pulmonary expression of interleukin-13 causes inflammation, mucus hypersecretion, subepithelial fibrosis, physiologic abnormalities, and eotaxin production. J. Clin. Invest. 103, 779-788 (1999).

17. Gilmour, J. \& Lavender, P. Control of IL-4 expression in T helper 1 and 2 cells. Immunology 124, 437-444 (2008).

18. Kashiwada, M. et al. IL-4-induced transcription factor NFIL3/E4BP4 controls IgE class switching. Proc. Natl. Acad. Sci. USA 107, 821-826 (2010).

19. Kopf, M. et al. Disruption of the murine IL-4 gene blocks Th2 cytokine responses. Nature 362, 245-248 (1993).

20. Ramalingam, T.R. et al. Unique functions of the type II interleukin 4 receptor identified in mice lacking the interleukin 13 receptor alpha1 chain. Nat. Immunol. 9, 25-33 (2008).

21. Busse, W.W. et al. Randomized trial of omalizumab (anti-lgE) for asthma in inner-city children. N. Engl. J. Med. 364, 1005-1015 (2011).

22. Wenzel, S. et al. Dupilumab in persistent asthma with elevated eosinophil levels. N. Engl. J. Med. 368, 2455-2466 (2013).

23. Maddox, J.F. et al. Lipoxin B4 regulates human monocyte/neutrophil adherence and motility: design of stable lipoxin B4 analogs with increased biologic activity. FASEB J 12, 487-494 (1998).

24. Gronert, K. et al. A role for the mouse 12/15-lipoxygenase pathway in promoting epithelial wound healing and host defense. J. Biol. Chem. 280 , 15267-15278 (2005).

25. Shen, J.C., Chen, B. \& Cohen, N.A. Keratinocyte chemoattractant (interleukin-8) regulation of sinonasal cilia function in a murine model. Int. Forum Allergy Rhinol. 2, 75-79 (2012).

26. Shen, J.C., Cope, E., Chen, B., Leid, J.G. \& Cohen, N.A. Regulation of murine sinonasal cilia function by microbial secreted factors. Int. Forum Allergy Rhinol. 2, 104-110 (2012).

27. Martin, N. et al. Primary human airway epithelial cell-dependent inhibition of human lung mast cell degranulation. PLOS ONE 7, e43545 (2012).

28. Gewirtz, A.T., Fokin, V.V., Petasis, N.A., Serhan, C.N. \& Madara, J.L. LXA4, aspirin-triggered 15-epi-LXA4, and their analogs selectively downregulate PMN azurophilic degranulation. Am. J. Physiol. 276, C988-C994 (1999).

29. Ariel, A., Chiang, N., Arita, M., Petasis, N.A. \& Serhan, C.N. Aspirintriggered lipoxin A4 and B4 analogs block extracellular signal-regulated kinase-dependent TNF-alpha secretion from human T cells. J. Immunol. 170, 6266-6272 (2003).

30. Starosta, V., Pazdrak, K., Boldogh, I., Svider, T. \& Kurosky, A. Lipoxin A4 counterregulates GM-CSF signaling in eosinophilic granulocytes. J. Immunol. 181, 8688-8699 (2008).

31. Soyombo, O., Spur, B.W. \& Lee, T.H. Effects of lipoxin A4 on chemotaxis and degranulation of human eosinophils stimulated by platelet-activating factor and $\mathrm{N}$-formyl-L-methionyl-L-leucyl-L-phenylalanine. Allergy 49, 230-234 (1994).

32. Barnig, C. et al. Lipoxin A4 regulates natural killer cell and type 2 innate lymphoid cell activation in asthma. Sci. Transl. Med. 5, 174ra126 (2013).

33. Kazani, S. et al. Exhaled breath condensate eicosanoid levels associate with asthma and its severity. J. Allergy Clin. Immunol. 132, 547-553 (2013).

34. Serhan, C.N., Hirsch, U., Palmblad, J. \& Samuelsson, B. Formation of lipoxin A by granulocytes from eosinophilic donors. FEBS Lett. 217, 242-246 (1987).

35. Romano, M. et al. Lipoxin synthase activity of human platelet 12lipoxygenase. Biochem. J. 296, 127-133 (1993).

36. Levy, B.D. et al. Human alveolar macrophages have 15-lipoxygenase and generate 15(S)-hydroxy-5,8,11-cis-13-trans-eicosatetraenoic acid and lipoxins. J. Clin. Invest. 92, 1572-1579 (1993).

37. Miyahara, S., Miyahara, N., Takeda, K., Joetham, A. \& Gelfand, E.W. Physiologic assessment of allergic rhinitis in mice: role of the high-affinity IgE receptor (FcepsilonRI). J. Allergy Clin. Immunol. 116, 1020-1027 (2005).

38. Levy, B.D. et al. Protectin D1 is generated in asthma and dampens airway inflammation and hyperresponsiveness. J. Immunol. 178, 496-502 (2007).

39. Bannenberg, G.L. et al. Molecular circuits of resolution: formation and actions of resolvins and protectins. J. Immunol. 174, 4345-4355 (2005).

40. Grutzkau, A. et al. LAMP-1 and LAMP-2, but not LAMP-3, are reliable markers for activation-induced secretion of human mast cells. Cytometry $A$ 61, 62-68 (2004).

41. Jensen, B.M., Beaven, M.A., Iwaki, S., Metcalfe, D.D. \& Gilfillan, A.M. Concurrent inhibition of kit- and FcepsilonRI-mediated signaling: coordinated suppression of mast cell activation. J. Pharmacol. Exp. Ther. 324, 128-138 (2008).

42. Dyer, K.D. et al. Functionally competent eosinophils differentiated ex vivo in high purity from normal mouse bone marrow. J. Immunol. 181, 4004-4009 (2008).

43. Blank, U. \& Rivera, J. Assays for regulated exocytosis of mast cell granules. Curr Protoc Cell Biol (Bonifacino, J.S. \& Dasso, M. \& Harford, J.B. \& Lippincott-Schawartz, J. \& Yamada, K.M., eds) 15.11.1-15.11.18 (Wiley \& Sons, New York, 2006). 